\title{
Using Service Innovation Model to Develop ICT Application Based on Service Science
}

\author{
Tung-Hsiang $\mathrm{Chou}^{+}$and Cheng-Lin $\mathrm{Wu}$ \\ National Kaohsiung First University of Science and Technology, Department of Information Management, \\ Taiwan
}

\begin{abstract}
In recent years, many governments are active in promoting e-business, they wants help enterprises to improve their profits and to create more value for themselves, so the Taiwan's government is to use "transformation" and "innovation" as the slogan and hope to break through the plight of economic growth and to push the enterprises into the international business[22][23].

This research uses a case study and invents the STEP2 research model to discuss some issues of ICT research, it also is developed based on innovation and user-oriented of service science and to combine ICT to achieve service innovation, then this research uses the strict BPM to solve the problems effectively where the problems exist in the business process. This research also discusses the mechanism of production management and ICT-Enabled production management system and implement service innovation and process innovation in the real case company.
\end{abstract}

Keywords: ICT, BPM, service innovation, process innovation, STEP².

\section{Introduction}

With countries are actively competing with each other in economic environment. Taiwan government proposes the "Three Industries, Four Reforms program" to help enterprises in their operations, they want to change and upgrade the industrial structure through this policy. The Three Industries, Four Reforms program are illustrated as follows: (1) Making the manufacturing industry service-oriented, (2) Making the services industry high-tech, (3) Globalizing the services industry, and (4) Making traditional Taiwanese industries specialty-oriented.

Many countries are actively promoting the Making the manufacturing industry service-oriented. As the Industry 4.0 is in order to cope with large number of customized order that is generated by customers, so they are proposed service-oriented architecture in manufacturing industry. The concept of industry 4.0 has built-in several aspects such as technology, service and process [8], [12].

With global human resource cost has increased, enterprise lacks in natural resources and encounters the globalization environmental competition impacts. German government and knowledge experts of academic institutions are strongly to conceive of industry 4.0 [2], [6]. However, Taiwan government also plans to implement Industry 4.0 concept, but there are existing four obstacles. Firstly, Taiwan companies lack complete digital factory layout and a complete plan. Secondly, management level will get fault digital information. Thirdly, only a few companies are able to effectively use the optimization of automated system and production simulation for manufacturing. Lastly, the digitization of data is not yet to reach a consensus between the enterprise and its suppliers [4].

Thus, this research applies user-oriented of service concept and interdisciplinary fields of service science and design to achieve innovative services. Because innovation is a key factor in business survival and to improve competitiveness business [7], it is including innovation of service design or process reengineering,

\footnotetext{
+ Corresponding author. Tel.: + $88676011000 \# 4129$.
}

E-mail address: Sam@nkfust.edu.tw. 
etc. It is able to push the services to be more efficient and to increase their revenue and using customer satisfaction as the main target in the enterprise.

In the other hand, this research needs to solve problems that were occurred in the case company. So it uses the spiritual of the Requirements Engineering [3] which is including Elicitation, Analysis, Negotiation and Validation four steps to analyse the case study.

\section{Literature Review}

This research focuses on service concept \& ICT application from Industry 4.0 related reference. This research also analyses the key business processes requirements and to solve issues of the case company.

\subsection{The service innovation}

Service is a group, an organization or individual entity to provide a service for another group, another organization or another individual entity [16] and it means that service is an activity or the process. Service does not have specification and standard [20]. And the main purpose of service science is to create knowledge, entity and value for the scientific, engineering and management. It uses the knowledge content and structure to create a workable knowledge system and uses the knowledge and systems to create more value.

In addition, government promotes innovation and transformation. Because innovation is the key factors in business survive and improve their competitiveness in the service science field [7]. Services science stresses the service should be designed based on user centric. It should be used the iterative design process to solve and validate user problems. And the design process must include the design, test, evaluate and over again [5].

\subsection{The application of technology}

Technology changes resources and meets human need. It is a strategy for human survival. It means that someone who uses knowledge of human, tools and skills to solve practical problems and extend human capabilities. It is the main tool for human usage to adapt the environment and so on [14]. It has been executed information process, communications and agreements used electronically, including the creation information, processing, storage, access and communication through information and communication technology (ICT) integration [1].

In this research, researcher performs data transformation across workstations through the Radio Frequency Identification (RFID) applications of ICT. Researcher also integrates business process and monitors the production line and return information to the factory of management repository through RFID [9][10][13][21]0. RFID was applied in the process of info read and info write, even if there were blocking obstacle the data transfer rate also difficult to affect accuracy. But, there is a very important key influence that must be avoided in the RFID data transfer process. The maximum amplitude of the interference metal will distort data transmitting through the electromagnetic waves and cause data error or undeliverable event [8].

\subsection{Optimization of Business Process}

Business Process Management (BPM) is a structure approach to analyse, maintain or improve enterprise business processes. Because leading in the BPM will affect the overall business processes of company. And it must comply with the following rules [15]: (1) the main activity of enterprise must be properly express and records. (2) BPM must be focus on the interaction between customers and main activities of enterprise. (3) BPM rely on systematic procedures to ensure that business processes are regular pattern and consistency. (4) BPM must be solved process problem and improved business processes through a gradual approach.

However, enterprises in order to express their major business processes and explore the problem through some way. Business Process Modelling Notation (BPMN) is a standard symbols use to represent business processes [18]. BPMN was developed by the ISO Business Process Management Initiative (BPMI), because business process composed of the structured activities, and BPMN be able to splits business activities into sub-processes and each activity has its own property and work [17], so users could be explained more clear information by visual expression. 


\section{Research Methodology}

This paper use both qualitative and quantify research simultaneously. Qualitative research through the four steps of requirements engineering [3], AT-ONE service development process [19][20]. Researcher needs to discuss the service project development process with the participants of product development and observe the production site. Quantitative research through statistical data analysis of this study to verify the benefit of the mechanism of production management and ICT-Enabled production management system. Therefore, this research process framework is shown in Fig. 1.

\begin{tabular}{|c|c|c|c|c|c|c|}
\hline $\begin{array}{c}\text { Field } \\
\text { Research }\end{array}$ & $\begin{array}{c}\text { Literature } \\
\text { Review } \\
\text { and Analysis }\end{array}$ & CO- Discuss & $\begin{array}{c}\text { System and } \\
\text { Process } \\
\text { design }\end{array}$ & $\begin{array}{c}\text { Field } \\
\text { verification }\end{array}$ & $\begin{array}{c}\text { Research } \\
\text { model design }\end{array}$ & $\begin{array}{c}\text { Effectiveness } \\
\text { analysis }\end{array}$ \\
\hline
\end{tabular}

Fig. 1: Research process framework.

\section{Case Study}

The case company established in 1994, and main business is metal surface treatment Original Equipment Manufacturer (OEM). When metal components of customers were produced finish who entrust case company execution surface treatment. The case company's current business is make to order, purchase, degreasing, sandblasting, paint coating and high bake. Factory area of company is large and considerable distance between each machine. If any error occurs during production and operator cannot instantly stop the machine or management personnel cannot make a immediately determine that will lead to huge losses for enterprise, such as goods or machine damage, machine stop working in production process, immaterial loss and so on. This paper help case company to design a set of electronic control systems for the manufacturing process and using innovative ideas of serving science, technology based on ICT and combine the BPM to make company control the production line in the real-time, then the information of factory will back to the knowledge management database for analysis and create information for policy makers. This research system operation diagram and system function diagram are shown in Fig. 2 and Fig. 3.

\section{Conclusions}

According to the industrial 4.0 literature review, this research indicates some issues and challenges of enterprise. This paper found that if the enterprise faces to the innovation and transformation. It must be improved from the business process. Because business processes are activities between the enterprise and customers. However, the purpose of BPM is to improve business processes through the survey, analysis of the process status and multi-reference successful cases and solutions. Enterprises must change the organizational culture or working method to improve business processes. And research results suggest that service will be generated benefits from the interaction of people, technology is also changing people's environment, and it is inevitable. People will use a variety of knowledge to create different technologies and people's requirement will vary with environment, processes and service experience. And research results show that environment, processes, services and technology will be interacted and to influence each other by people. People generate the need to cause environment to change. People and environment will also cause the process change. People driven services innovation. Environment, processes, services and people will accelerate the development of technology. Finally, this paper develops STEP2 research model.

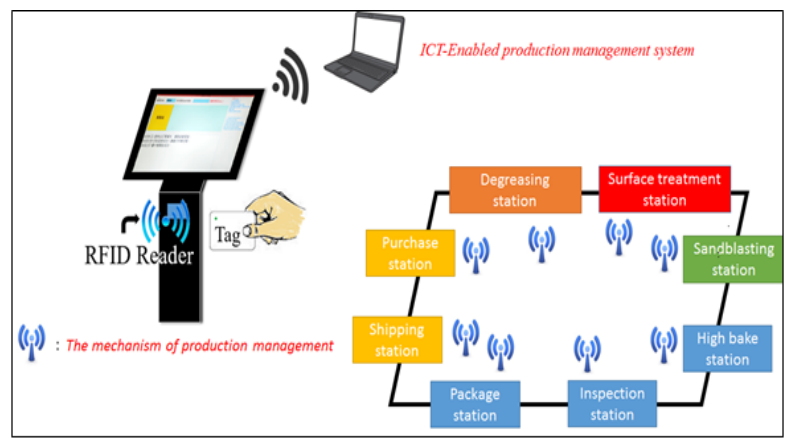

Fig. 2: Schematic diagram of system operation.

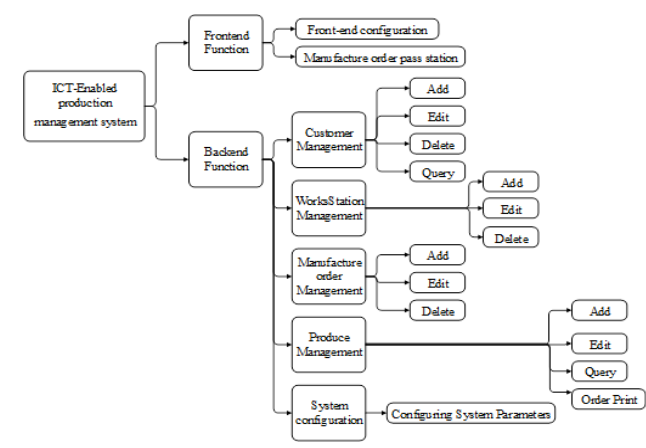

Fig. 3: Function diagram of system.

\section{Acknowledgement}


This research is partially sponsored by Ministry of Science and Technology grant no. 104-2410-H-327 $013-$.

\section{References}

[1] A. Creti. Network technologies, communication externalities and total factor productivity. Structural Change and Economic Dynamics. 2001, 12(1): 1-28.

[2] Bundesministerium für Wirtschaft und Energie. What is Industrie 4.0? Germany Bundesministerium für Wirtschaft und Energie, 2015. URL: http://www.plattform-i40.de/I40/Navigation/DE/Home/home.html.

[3] I. Sommerville, G. Kotonya. Requirements engineering: processes and techniques. John, Wiley \& Sons, Inc. 1998.

[4] iThome. Siemens: Taiwan to learn from the German Industry 4.0 has four major challenges. Taipei, Taiwan, 2015. URL: http://www.ithome.com.tw/news/96445.

[5] J. D. Gould, C. Lewis. Designing for usability: key principles and what designers think. Communications of the ACM. 1985, 28(3): 300-311.

[6] J. Lee, H.A. Kao, S. Yang. Service innovation and smart analytics for industry 4.0 and big data environment. Procedia CIRP. 2014, 16:3-8.

[7] J. Sheehan. Understanding service sector innovation. Communications of the ACM. 2006, 49(7):42-47.

[8] J. Song, C.T. Haas, C. Caldas, E. Ergen, B. Akinci. Automating the task of tracking the delivery and receipt of fabricated pipe spools in industrial projects. Automation in Construction. 2006, 15(2): 166-177.

[9] J. Tan, H. Wang, Dan Li, Q. Wang. A RFID architecture built in production and manufacturing fields. 3rd International Conference on Convergence and Hybrid Information Technology (ICCIT'08). 2008, 1: 1118-1120.

[10] J. Wang, Z. Luo, E. C. Wong, C.J. Tan. RFID assisted object tracking for automating manufacturing assembly lines. IEEE International Conference on e-Business Engineering (ICEBE 2007). 2007, 48-53.

[11] J. Y. Ku, R. W. Bo. Operations Management in Service Industries. Hwa Tai Publishing, Taipei, Taiwan, 2012.

[12] J.C. Wei. Future development trends and opportunities of Industry 4.0 wisdom plan. Taipei, Taiwan: Market Intelligence \& Consulting Institute, 2015.

[13] L. Li, F. Pan, J. Tan, T. Shi, J. Liu. Pricing and ordering decision for perishable food supply chain with RFID technology. Information Management and Management Engineering. 2015, 94: 459.

[14] M. Hacker, R. A. Barden. Technology in Our World. Delmar Publishers: Albany, NY, USA, 1987.

[15] M. Zairi. Business process management: a boundary less approach to modern competitiveness. Business Process Management Journal.1997, 3(1): 64-80.

[16] P. Kotler. Principles of Marketing. London. Prentice-Hall, 1980.

[17] R. M. Dijkman, M. Dumas, C. Ouyangc. Semantics and analysis of business process models in BPMN. Information and Software Technology. 2008, 50(12): 1281-1294.

[18] S. A. White. Introduction to BPMN. IBM Cooperation 2.0, 2004.

[19] S. Clatworthy. Service innovation through touch-points: Development of an innovation toolkit for the first stages of new service development. International Journal of Design, 2011. 5: 15-28.

[20] S. Marc, J. Schneider. This Is Service Design Thinking: Basics, Tools and Cases. John, Wiley \& Sons. Inc., 2012.

[21] S. Piramuthu. Protocols for RFID tag/reader authentication. Decision Support Systems, 2007. 43(3): 897-914.

[22] Small and Medium Enterprise Administration. White Paper on Small and Medium Enterprises in Taiwan. Taipei: Small and Medium Enterprise Administration, 2015.

[23] Small and Medium Enterprise Administration. White Paper on Small and Medium Enterprises in Taiwan. Taipei: Small and Medium Enterprise Administration, 2014.

Y. Rekik, E. Sahin, Y. Dallery. Analysis of the impact of the RFID technology on reducing product misplacement errors at retail stores. International Journal of Production Economics. 2008, 112(1): 264-278. 